\title{
RESPON PERTUMBUHAN TUNAS SANINTEN (Castanopsis argentea (Blume) A.DC.) TERHADAP PEMBERIAN ZAT PENGATUR TUMBUH BAP DAN IAA SECARA IN VITRO
}

\author{
The growth response of Saninten (Castanopsis argentea (Blume) A.DC.) In Vitro by Adding \\ Plant Growth Regulator BAP and IAA
}

\author{
Arum Sekar Wulandari ${ }^{1}$, Erina Sulistiani ${ }^{2}$ dan Esthi Liani Agustiani ${ }^{1}$ \\ ${ }^{1}$ Departemen Silvikultur, Fakultas Kehutanan IPB \\ ${ }^{2}$ Peneliti SEAMEO BIOTROP, Bogor
}

\begin{abstract}
Saninten (Castanopsis argentea (Blume) A.DC.) is one of the member Fagaceae family which can produce wood and non-wood product. Micropropagation of saninten by in vitro has never been reported. This research aims to identify the growth response of saninten shoot by adding Plant Growth Regulator (PGR), they are 6-benzylaminopurine (BAP) and indole-3-acetic-acid (IAA) with different concentrations in propagation in vitro on woody plant medium (WPM). The research conducted a completely randomized design (CRD) factorial. They are PGR type and PGR concentration. The $P G R$ type consist of two levels namely BAP and IAA. PGR concentration consist of three levels namely $0 \mathrm{mg} / L$ BAP and $I A A, 0.5 \mathrm{mg} / \mathrm{L}$ BAP or $0.1 \mathrm{mg} / \mathrm{L} I A A$, and $1.0 \mathrm{mg} / \mathrm{L} \mathrm{BAP}$ or $0.1 \mathrm{mg} / \mathrm{L}$ IAA. Parameters observed is the amount of shoot, shoot height, and callus growth. The combination of BAP $(0,0.5,1 \mathrm{mg} / \mathrm{L})$ and $I A A(0,0.1,0.1 \mathrm{mg} / \mathrm{L})$ haven't produce optimal growth of shoot. WPM medium with $0.5 \mathrm{mg} / \mathrm{L}$ BAP was able to produce the best of percentage of shoot, the number of shoots, and shoot height growth. WPM medium with IAA concentration of 0.1 and $0.2 \mathrm{mg} / \mathrm{L}$ produce explant with callus.
\end{abstract}

Key words: 6-benzylaminopurine (BAP), Castanopsis argentea, indole-3-acetic-acid (IAA), woody plant medium (WPM)

\section{PENDAHULUAN}

Saninten (Castanopsis argentea (Blume) A.DC.) adalah salah satu anggota famili Fagaceae yang merupakan penghasil kayu dan non kayu. Kayu saninten biasanya digunakan untuk kayu pertukangan (Martawijaya et al. 1987), sedangkan hasil hutan non kayu dari saninten berupa buah dan bahan pewarna dari kulit buahnya. Secara ekologi, pohon ini menjadi tempat bagi satwa liar (terutama burung dan mamalia) untuk mencari pakan, beristirahat dan bersarang (Heriyanto et al. 2007). Jenis ini juga dapat digunakan untuk mereboisasi lahan dengan kandungan batu yang tinggi (Wibowo 2006), serta menjadi salah satu jenis tanaman yang berpotensi untuk kegiatan revegetasi lahan bekas tambang (Mansur 2013).

Manfaat dari tanaman saninten menjadi salah satu alasan pentingnya upaya perbanyakan tanaman saninten untuk menunjang keberadaan dan kebutuhan akan jenis ini. Perbanyakan secara generatif melalui permudaan alam untuk jenis ini sulit dilakukan karena buahnya yang disenangi satwa (Heriyanto et al. 2007). Selain itu, lamanya pertumbuhan dan perkembangan tanaman kehutanan menjadi alasan untuk ditemukannya teknik perbanyakan secara vegetatif yang cepat dan menghasilkan individu tanaman yang unggul.

Perbanyakan saninten secara vegetatif telah dilakukan oleh Fitria (2015) melalui stek pucuk dengan persentase stek hidup sebesar $92.78 \%$ dan stek berakar sebesar $40.56 \%$ pada umur 45 hari. Namun perbanyakan dengan metode ini terkendala serangan fungi yang muncul di bagian pangkal stek pucuk pada beberapa stek yang hidup. Teknik perbanyakan vegetatif lainnya yang dapat dipilih ialah perbanyakan tanaman melalui kultur jaringan, dengan keunggulan: (1) sifat genetik yang sama dengan pohon induknya, (2) dapat diperbanyak dalam skala besar, dan (3) waktu relatif singkat (Sulistiani dan Yani 2012). Perbanyakan saninten secara in vitro belum pernah dilaporkan. Lestari (2008) menyatakan keberhasilan tanaman melalui teknik kultur jaringan dipengaruhi oleh keberadaan zat pengatur tumbuh (ZPT). Oleh karena itu, penelitian ini bertujuan untuk mengidentifikasi respon pertumbuhan tunas saninten terhadap pemberian 6benzylaminopurine (BAP) dan indole-3-acetic-acid (IAA) dengan konsentrasi yang berbeda secara in vitro.

\section{METODE}

\section{Waktu dan Lokasi Penelitian}

Penelitian ini dilaksanakan pada bulan September 2015 sampai dengan April 2016. Penelitian dilakukan di Laboratory Service Southeast Asian Regional Center for Tropical Biology (SEAMEO BIOTROP). 


\section{Alat dan Bahan}

Alat-alat yang digunakan dalam penelitian ini adalah botol kultur, gelas ukur, labu ukur, cawan petri, pipet, pipet bulb, sendok pengaduk, pemanas, gunting, pinset, pisau (scapel), bunsen, sprayer, pH meter, karet gelang, timbangan analitik (ketelitian 10-4), magnetic stirrer, magnetic stirring bars, oven, autoklaf, laminar air flow cabinet (LAFC), ruang transfer/subkultur, dan ruang kultur.

Bahan yang digunakan dalam penelitian ini adalah tunas pucuk saninten dari bibit berumur 2 tahun, kertas milimeter, tissue, dan plastik. Bahan kimia yang digunakan yaitu komponen media dasar woody plant medium (WPM), zat pengatur tumbuh (ZPT) berupa 6benzylaminopurine (BAP) dan indole-3-acetic-acid (IAA). Bahan sterilan yaitu fungisida (bahan aktif: benomil $50.4 \%$ ), bakterisida (bahan aktif: streptomisin sulfat 20\%), desinfektan (bahan aktif: natrium hipoklorit $5.25 \%$ ), tween 20 , alkohol $70 \%$ dan aquades steril.

\section{Prosedur Penelitian}

\section{Penyiapan bahan tanaman}

Bibit saninten dipangkas untuk mendapatkan tunas baru, serta dilakukan penyemprotan bibit setiap dua hari sekali menggunakan larutan fungisida dan bakterisida dengan konsentrasi masing-masing $2 \mathrm{~g} / \mathrm{L}$.

\section{Sterilisasi alat dan bahan}

Peralatan dan bahan penunjang kegiatan kultur disterilisasi menggunakan autoklaf pada suhu $121{ }^{0} \mathrm{C}$ selama 15 menit, kemudian disimpan dalam oven dengan suhu $80{ }^{\circ} \mathrm{C}$ sampai alat tersebut digunakan. Alat logam disterilisasi sesaat sebelum digunakan dengan mencelupkannya ke dalam alkohol 70\% lalu dipanaskan di atas bunsen yang menyala.

\section{Sterilisasi lingkungan kerja}

LAFC disemprot alkohol $70 \%$ pada bagian dinding sebelum dilakukan penanaman eksplan. Tangan pekerja disterilkan dengan menyemprotkan alkohol $70 \%$, serta menggunakan jas laboratorium dan masker selama di ruang kultur.

\section{Penyediaan aquades steril}

Air hasil penyulingan (destilasi) dimasukkan ke dalam botol kaca bertutup, kemudian disterilkan dalam autoklaf pada suhu $121{ }^{\circ} \mathrm{C}$ selama 30 menit. Aquades steril kemudian disimpan dalam ruang transfer/subkultur.

\section{Pembuatan media}

Media yang digunakan adalah media WPM. Media inisiasi ditambahkan BAP $0.5 \mathrm{mg} / \mathrm{L}$, sedangkan media induksi (perlakuan) ditambahkan kombinasi ZPT BAP $(0,0.5,1 \mathrm{mg} / \mathrm{L})$ dan IAA $(0,0.1,0.2 \mathrm{mg} / \mathrm{L})$. Pembuatan media dilakukan dengan mencampurkan larutan bahan baku (unsur hara makro, mikro, vitamin, ZPT, sukrosa) menggunakan pipet sesuai konsentrasi yang ditetapkan ke dalam labu ukur berisi $1000 \mathrm{~mL}$ aquades. Larutan media diaduk di atas magnetic stirrer. Setelah itu $\mathrm{pH}$ diatur hingga 5.7, kemudian dimasukkan agar-agar (phytagel) sebanyak $2 \mathrm{~g} / \mathrm{L}$ sebagai bahan pemadat media. Media dipanaskan hingga mendidih, kemudian dituang ke dalam botol kultur sebanyak $\pm 20 \mathrm{~mL} /$ botol. Botol ditutup plastik dan direkatkan dengan karet, kemudian disterilisasi di dalam autoklaf pada suhu 121 ${ }^{0} \mathrm{C}$ selama 15 menit.

\section{Sterilisasi eksplan}

Sterilisasi tunas saninten disterilisasi melalui 2 tahap. Tahap pertama dilakukan di luar LAFC dengan 3 macam perendaman yang dilakukan secara berurutan, yaitu perendaman dalam $100 \mathrm{~mL}$ aquades +3 tetes tween 20 (30 menit), perendaman dalam larutan fungisida $2 \mathrm{~g} / \mathrm{L}+3$ tetes tween 20 (60 menit), dan perendaman dalam larutan bakterisida $2 \mathrm{~g} / \mathrm{L}+3$ tetes tween 20 (60 menit). Setiap tahap perendaman diikuti pembilasan dengan aquades sebanyak 3 kali. Tahap kedua dilakukan perendaman dengan desinfektan berupa larutan natrium hipoklorit $(\mathrm{NaOCl} 5.25 \%)$ di dalam LAFC. Perendaman eksplan dengan $\mathrm{NaOCl}$ $5.25 \%$ dilakukan dengan 4 macam metode perendaman (Tabel 1)

Tabel 1 Perbandingan prosedur metode sterilisasi pada kultur saninten

\begin{tabular}{ccc}
\hline Metode & $\begin{array}{c}\text { Konsentrasi NaOCl } \\
5.25 \%^{*}(\%)\end{array}$ & $\begin{array}{c}\text { Lama perendaman } \\
\text { (menit) }\end{array}$ \\
\hline 1 & 15 & 15 \\
2 & 15 & 10 \\
3 & 10 & 15 \\
4 & 10 & 10 \\
\hline
\end{tabular}

*Larutan $\mathrm{NaOCl} 5.25 \%$ dicampur dengan 3 tetes tween 20.

Eksplan yang sudah melalui tahap sterilisasi ditanam (diinisiasi) dalam media WPM dengan ZPT BAP 0.5 mg/L. Peubah yang diamati meliputi eksplan terkontaminasi (fungi, bakteri, fungi dan bakteri), mati dan steril. Setiap peubah dihitung dengan cara:

$$
\begin{aligned}
& \% \text { eksplan kontaminasi }=\frac{\sum \text { eksplan kontaminasi }}{\sum \% \text { eksplan tanam }} \times 100 \% \\
& \% \text { eksplan mati }=\frac{\sum \text { eksplan mati }}{\sum \text { eksplan tanam }} \times 100 \% \\
& \% \text { steril }=100 \%-(\% \text { kontaminasi }+\% \text { mati })
\end{aligned}
$$

\section{Pemindahan eksplan ke media perlakuan}

Eksplan steril yang telah diinisiasi dalam media WPM dengan BAP $0.5 \mathrm{mg} / \mathrm{L}$ kemudian diinduksi ke dalam media perlakuan. Percobaan dilakukan dengan menggunakan rancangan acak lengkap (RAL) faktorial, dengan 2 faktor yaitu macam ZPT dan konsentrasi ZPT. Macam ZPT terdiri atas 2 taraf yaitu BAP dan IAA. Konsentrasi ZPT terdiri atas 3 taraf yaitu BAP dan IAA $0 \mathrm{mg} / \mathrm{L}$, BAP $0.5 \mathrm{mg} / \mathrm{L}$ atau IAA $0.1 \mathrm{mg} / \mathrm{L}$, dan BAP $1.0 \mathrm{mg} / \mathrm{L}$ atau IAA $0.2 \mathrm{mg} / \mathrm{L}$. Masing-masing perlakuan memiliki 4 ulangan dengan 2 unit amatan pada setiap ulangan. Pengambilan keputusan berdasarkan sidik ragam yakni: (1) tolak $\mathrm{H} 0$ jika nilai $\mathrm{F}$ hitung $>\mathrm{F}$ tabel, (2) terima Ho jika F hitung < F tabel. 


\section{Pemeliharaan}

Botol kultur disimpan dalam rak pada ruang kultur dengan suhu udara $22-25{ }^{\circ} \mathrm{C}$ dan diletakkan di bawah lampu fluorescent 36-40 watt sebanyak 1 buah. Lamanya penyinaran lampu diatur 16 jam menyala dan 8 jam padam.

\section{Pertumbuhan tunas saninten}

Pertumbuhan dan perkembangan eksplan kemudian diamati selama 8 minggu setelah tanam (MST). Peubah yang diukur di antaranya:

Waktu munculnya tunas. Pengamatan dilakukan setiap hari dengan melihat perkembangan kemunculan tunas pada eksplan.

Jumlah tunas. Jumlah tunas dihitung pada saat akhir pengamatan yaitu pada 8 MST dengan cara menghitung jumlah tunas yang terbentuk.

Tinggi tunas. Tinggi tunas diukur dari selisih tinggi tunas pada akhir pengamatan dengan tinggi tunas saat masuk media perlakuan. Pengukuran dilakukan menggunakan kertas milimeter yang diletakan di bawah cawan petri.

Waktu munculnya kalus. Pengamatan dilakukan setiap hari dengan melihat perkembangan kemunculan kalus pada eksplan.

Ukuran kalus. Penetapan skor pada eksplan berkalus dilakukan berdasarkan kriteria penilaian pada Tabel 2.

Tabel 2 Kriteria penetapan skor pada eksplan berkalus

\begin{tabular}{cl}
\hline Skor & \multicolumn{1}{c}{ Kriteria } \\
\hline 0 & $\begin{array}{l}\text { Eksplan hidup namun tidak membentuk kalus } \\
1\end{array}$ \\
& $\begin{array}{l}\text { Eksplan membentuk sangat sedikit kalus (bagian } \\
\text { eksplan yang tertanam media menggembung hingga } \\
\text { belah) }\end{array}$ \\
2 & $\begin{array}{l}\text { Eksplan membentuk kalus yang sedikit (terdapat } \\
\text { bulatan kalus dengan diameter }<0.5 \mathrm{~cm} \text { ) }\end{array}$ \\
3 & $\begin{array}{l}\text { Eksplan membentuk kalus sedang (kalus muncul } \\
\text { berbentuk remah dengan diameter kalus }>0.5-1.0 \\
\mathrm{~cm})\end{array}$ \\
4 & $\begin{array}{l}\text { Eksplan membentuk kalus banyak (kalus muncul } \\
\text { dengan diameter }>1.0 \text { cm) }\end{array}$ \\
5 & $\begin{array}{l}\text { Eksplan membentuk kalus sangat banyak (kalus } \\
\text { membentuk organ atau plantlet) }\end{array}$ \\
&
\end{tabular}

\section{Analisis Data}

Pengaruh perlakuan yang dicobakan terhadap data yang menggunakan skor dianalisis dengan menggunakan statistik non parametrik Kruskal-Wallis. Data jumlah tunas dan tinggi tunas diuji dengan analisis ragam (uji F). Perbedaan yang berpengaruh nyata pada uji F diuji lanjut dengan menggunakan Duncan Multiple Range Test (DMRT) pada taraf kesalahan 5\%. Pengolahan data dilakukan dengan menggunakan software SPSS (Statistical Package for Social Sciences)

\section{HASIL DAN PEMBAHASAN}

Hasil

\section{Sterilisasi eksplan}

Hasil perbandingan metode sterilisasi eksplan pucuk saninten disajikan pada Gambar 1.

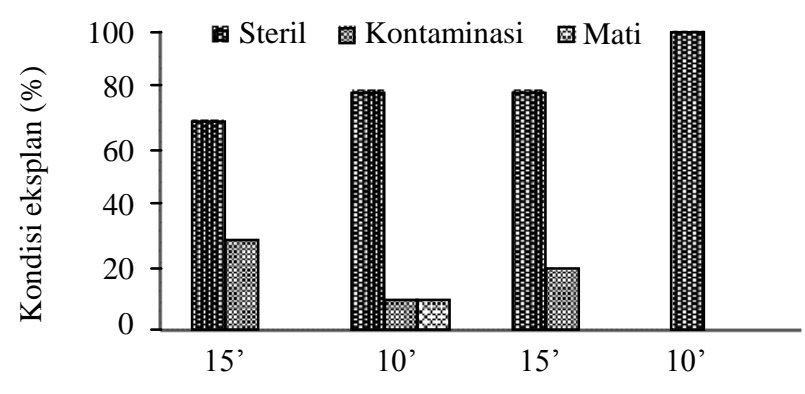

$\mathrm{NaOCl}(\%)$ - lama perendaman (menit)

Gambar 1 Pengaruh metode sterilisasi terhadap eksplan saninten steril yang dihasilkan pada 4 MST

Metode perendaman eksplan dengan larutan $\mathrm{NaOCl}$ $5.25 \%$ konsentrasi $15 \%$ selama 10 dan 15 menit mampu menghasilkan eksplan steril yang tinggi, namun terdapat eksplan steril yang mengalami pencoklatan (browning). Metode perendaman eksplan dengan larutan $\mathrm{NaOCl}$ $5.25 \%$ konsentrasi $10 \%$ selama 10 menit mampu menghasilkan $100 \%$ eksplan steril (Gambar 1), namun setelah 4 MST terjadi perubahan kondisi eksplan berupa munculnya kontaminan pada beberapa eksplan. Oleh karena itu, efektivitas metode sterilisasi terbaik yang dipilih ialah perendaman eksplan dengan larutan $\mathrm{NaOCl}$ $5.25 \%$ konsentrasi $10 \%$ selama 15 menit.

Tabel 3 Hasil sterilisasi eksplan saninten dengan perendaman desinfektan (NaOCl $5.25 \%)$ konsentrasi $10 \%$ selama 15 menit pada 4 MST

\begin{tabular}{ccccc}
\hline Sterilisasi & \multirow{2}{*}{$\begin{array}{c}\text { Jumlah } \\
\text { eksplan }\end{array}$} & \multicolumn{3}{c}{ Kondisi eksplan (\%) } \\
\cline { 3 - 5 } & 19 & Steril & Kontaminasi & Mati \\
\hline 1 & 49 & 44.21 & 15.79 & 0.00 \\
2 & 24 & 54.17 & 55.10 & 0.00 \\
3 & 12 & 33.33 & 66.67 & 4.17 \\
4 & &
\end{tabular}

*Sterilisasi dilakukan pada waktu yang berbeda. Eksplan steril kemudian digunakan pada perlakuan berikutnya.

Persentase eksplan steril yang didapatkan berkisar antara $33.33 \%$ hingga $84.21 \%$ (Tabel 3). Adanya kontaminasi pada eksplan saninten disebabkan oleh mikroorganisme berupa fungi dan bakteri. Waktu munculnya kontaminan pada eksplan berbeda-beda, namun umumnya terjadi ketika 3 hari setelah tanam. 


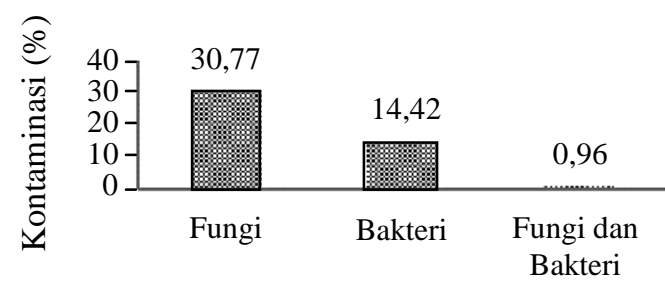

Jenis kontaminan

Gambar 2 Jenis kontaminan pada fase inisiasi tunas saninten selama 4 MST

Kontaminasi tertinggi dalam penelitian ini disebabkan oleh fungi sebesar $30.77 \%$ (Gambar 2). Kontaminasi oleh bakteri terjadi sebesar $14.42 \%$, sedangkan kontaminasi oleh fungi dan bakteri sebesar $0.96 \%$.

\section{Pertumbuhan tunas}

\section{Jumlah tunas}

Hasil analisis ragam jumlah tunas saninten pada umur 8 MST menunjukkan bahwa faktor jenis ZPT, konsentrasi ZPT dan interaksi keduanya tidak berpengaruh nyata terhadap jumlah tunas yang terbentuk. Eksplan saninten yang diinduksikan ke dalam media perlakuan menunjukkan respon berupa kemunculan tunas (Tabel 4).

Tabel 4 Pengaruh BAP dan IAA pada media induksi (WPM) terhadap kemunculan tunas saninten pada umur 8 MST

\begin{tabular}{ccccc}
\hline $\begin{array}{c}\text { BAP } \\
(\mathrm{mg} / \mathrm{L})\end{array}$ & $\begin{array}{c}\text { IAA } \\
(\mathrm{mg} / \mathrm{L})\end{array}$ & $\begin{array}{c}\text { Rentang waktu } \\
\text { pertunasan } \\
(\mathrm{HST})\end{array}$ & $\begin{array}{c}\text { Eksplan } \\
\text { bertunas } \\
(\%)\end{array}$ & $\begin{array}{c}\text { Rentang } \\
\text { jumlah } \\
\text { tunas }\end{array}$ \\
\hline 0.0 & 0.0 & 0 & 0.0 & 0 \\
0.5 & 0.0 & $14-42$ & 37.5 & $0-8$ \\
1.0 & 0.0 & $14-28$ & 25.0 & $0-3$ \\
0.0 & 0.1 & $7-10$ & 25.0 & $0-2$ \\
0.5 & 0.1 & $7-14$ & 25.0 & $0-2$ \\
1.0 & 0.1 & $7-14$ & 25.0 & $0-2$ \\
0.0 & 0.2 & 0 & 0.0 & 0 \\
0.5 & 0.2 & $10-14$ & 25.0 & $0-3$ \\
1.0 & 0.2 & 10 & 12.5 & $0-3$ \\
\hline
\end{tabular}

Berdasarkan pengamatan, hampir semua perlakuan mampu menghasilkan eksplan bertunas kecuali pada media kontrol dan media WPM dengan IAA $0.2 \mathrm{mg} / \mathrm{L}$. Kemunculan tunas tercepat dimulai pada waktu 7 HST, dan waktu kemunculan tunas paling lama terjadi pada 42 HST. Tabel 4 menunjukkan bahwa persentase eksplan bertunas tertinggi sebesar $37.5 \%$ hanya terjadi dalam media WPM dengan BAP $0.5 \mathrm{mg} / \mathrm{L}$. Sama halnya dengan jumlah tunas yang dihasilkan, jumlah tunas tertinggi sebesar 8 tunas terjadi pada media WPM dengan BAP $0.5 \mathrm{mg} / \mathrm{L}$.

\section{Tinggi tunas}

Hasil analisis ragam jumlah tunas saninten pada umur 8 MST menunjukkan bahwa faktor jenis ZPT, konsentrasi ZPT dan interaksi keduanya tidak berpengaruh nyata terhadap pertambahan tinggi eksplan tunas saninten.

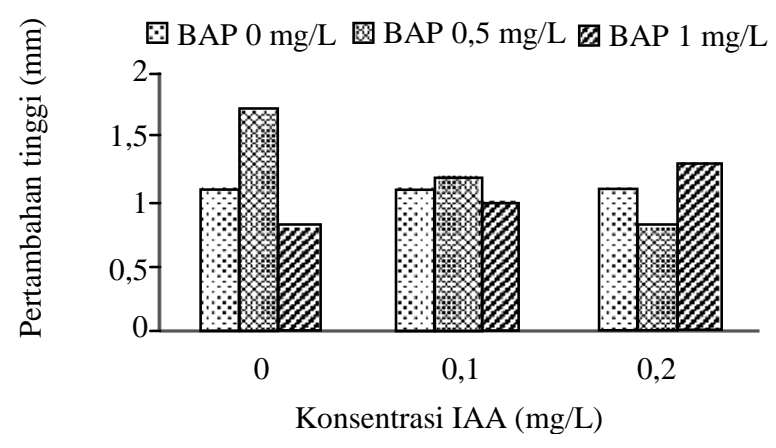

Gambar 3 Pertambahan tinggi tunas saninten dalam media WPM dengan kombinasi ZPT BAP $(0$, $0.5,1 \mathrm{mg} / \mathrm{L})$ dan IAA $(0,0.1,0.2 \mathrm{mg} / \mathrm{L})$ pada umur 8 MST

Gambar 3 menunjukkan bahwa perlakuan media WPM BAP $0 \mathrm{mg} / \mathrm{L}$ dengan IAA pada berbagai konsentrasi $(0, \quad 0.1, \quad 0.2 \quad \mathrm{mg} / \mathrm{L})$ menghasilkan pertambahan tinggi tunas yang sama, yaitu sebesar 1.1 mm. Perlakuan media WPM BAP $0.5 \mathrm{mg} / \mathrm{L}$ yang dikombinasikan dengan IAA pada berbagai konsentrasi $(0,0.1,0.2 \mathrm{mg} / \mathrm{L})$ menghasilkan pertambahan tinggi tunas yang semakin menurun seiring dengan penambahan konsentrasi IAA. Respon sebaliknya terjadi pada perlakuan media WPM dengan ZPT BAP 1 $\mathrm{mg} / \mathrm{L}$ yang dikombinasikan dengan IAA pada berbagai konsentrasi $(0,0.1,0.2 \mathrm{mg} / \mathrm{L})$, terjadi peningkatan pertambahan tinggi tunas seiring dengan penambahan konsentrasi IAA. Perlakuan terbaik dalam menghasilkan pertambahan tinggi tunas terjadi pada perlakuan media WPM dengan ZPT BAP $0.5 \mathrm{mg} / \mathrm{L}$ dengan nilai sebesar $1.7 \mathrm{~mm}$

\section{Pertumbuhan kalus}

Hasil analisis Kruskal Wallis terhadap skor berupa kemunculan kalus pada eksplan tunas saninten pada 8 MST menunjukkan hasil yang tidak berpengaruh nyata. Setelah 8 MST, terdapat beberapa kondisi eksplan seperti yang disajikan pada Tabel 5.

Tabel 5 Pengaruh BAP dan IAA pada media induksi (WPM) terhadap kemunculan kalus, kematian eksplan dan kontaminasi eksplan

\begin{tabular}{ccccrc}
\hline $\begin{array}{c}\text { BAP } \\
(\mathrm{mg} / \mathrm{L})\end{array}$ & $\begin{array}{c}\text { IAA } \\
(\mathrm{mg} / \mathrm{L})\end{array}$ & $\begin{array}{c}\text { Rentang } \\
\text { waktu } \\
\text { kemunculan } \\
\text { kalus (HST) }\end{array}$ & $\begin{array}{c}\text { Eksplan } \\
\text { berkalus } \\
(\%)\end{array}$ & $\begin{array}{c}\text { Eksplan } \\
\text { mati }(\%)\end{array}$ & $\begin{array}{c}\text { Eksplan } \\
\text { terkontaminasi } \\
(\%)\end{array}$ \\
\hline 0.0 & 0.0 & 0 & 0.0 & 0.0 & 25.0 \\
0.5 & 0.0 & $10-48$ & 37.5 & 12.5 & 0.0 \\
1.0 & 0.0 & $10-48$ & 37.5 & 12.5 & 25.0 \\
0.0 & 0.1 & $10-32$ & 50.0 & 0.0 & 25.0 \\
0.5 & 0.1 & $14-48$ & 50.0 & 25.0 & 12.5 \\
1.0 & 0.1 & $14-48$ & 62.5 & 12.5 & 0.0 \\
0.0 & 0.2 & $10-48$ & 75.0 & 0.0 & 12.5 \\
0.5 & 0.2 & 14 & 25.0 & 12.5 & 12.5 \\
1.0 & 0.2 & $10-49$ & 50.0 & 12.5 & 12.5 \\
\hline
\end{tabular}

Respon kalus muncul di seluruh perlakuan media induksi kecuali pada media tanpa ZPT (kontrol). Kalus umumnya muncul pada 10 dan 14 HST. Persentase 
eksplan berkalus tertinggi pada WPM dengan IAA 0.2 $\mathrm{mg} / \mathrm{L}$ (Tabel 5). Media WPM + BAP $1 \mathrm{mg} / \mathrm{L}$ + IAA 0.1 $\mathrm{mg} / \mathrm{L}$ memiliki persentase eksplan berkalus kedua, namun kualitas kalus yang baik pada media tersebut hanya terjadi pada satu eksplan. Media induksi yang menghasilkan persentase kalus tinggi dengan kualitas kalus yang baik setelah media WPM dengan IAA 0.2 $\mathrm{mg} / \mathrm{L}$ adalah media WPM dengan IAA $0.1 \mathrm{mg} / \mathrm{L}$. Pada media tersebut terdapat eksplan dengan kalus yang berorganogenesis menjadi akar.

\section{Pembahasan}

\section{Sterilisasi eksplan}

Kegiatan dalam kultur jaringan dimulai dengan tahap sterilisasi bahan tanam (eksplan), inisiasi eksplan, induksi dan multiplikasi, kemudian dilakukan tahap aklimatisasi atau pengakaran (Hendaryono dan Wijayani 2012). Proses sterilisasi eksplan dilakukan untuk menghilangkan sumber kontaminan yang tidak diinginkan dengan gangguan seminimal mungkin pada eksplan. Berdasarkan konsentrasi dan waktu perendaman eksplan dalam larutan $\mathrm{NaOCl} 5.25 \%$, metode perendaman eksplan dalam larutan $\mathrm{NaOCl}$ $5.25 \%$ konsentrasi $10 \%$ selama 15 menit lebih baik karena mampu menghasilkan eksplan steril yang stabil kondisinya pada 4 MST serta kematian eksplan akibat browning yang rendah $(0.96 \%)$. Persentase eksplan steril tertinggi dan terendah dari hasil sterilisasi menggunakan metode ini sebesar $84.21 \%$ dan $33.33 \%$. Pada sterilisasi eksplan tembesu (Fagraea fragrans Roxb) oleh Ardiansyah (2014), penggunaan larutan $\mathrm{NaOCl} 0.5 \%$ selama 15 dan 20 menit menghasilkan eksplan tembesu steril sebesar $26.67 \%$ dan $33.33 \%$. Kondisi tersebut menunjukkan bahwa konsentrasi yang tepat dari bahan sterilan dan pemilihan waktu lamanya eksplan terpapar bahan sterilan mampu meminimalkan kerusakan eksplan dan menjaga peluang hidup eksplan.

Adanya kontaminan pada eksplan hasil sterilisasi diduga disebabkan oleh proses sterilisasi yang kurang optimal. Zulkarnain (2009) menyatakan bahwa sumber kontaminasi mikroorganisme pada sistem kultur jaringan dapat berasal dari beberapa faktor, seperti faktor medium dan alat yang tidak sempurna sterilisasinya, lingkungan kerja yang kurang steril, eksplan, dan pekerjaan yang kurang teliti. Pada kultur eksplan saninten, kontaminasi tetap terjadi dengan persentase kontaminasi tertinggi disebabkan oleh fungi sebesar $30.77 \%$. Hal serupa juga terjadi pada penelitian yang dilakukan oleh Khairunisa (2009), kontaminasi terbesar dalam inisiasi tunas binahong (Anredera cordifolia [Ten.] Steenis) disebabkan oleh fungi.

Sumber kontaminasi pada eksplan dapat disebabkan oleh kontaminan yang berasal dari dalam jaringan tanaman sehingga tidak dapat dihilangkan hanya dengan sterilisasi permukaan, seperti adanya bakteri endofit pada jaringan tanaman (Zulkarnain 2009). Adanya penyerapan unsur hara dari media oleh eksplan, akan mendorong bakteri endofit dalam jaringan tanaman terbawa keluar dan berkembang pada media. Kondisi lingkungan in vitro dengan unsur hara dan sukrosa dalam jumlah besar, kelembaban yang tinggi, dan suhu yang hangat dapat mendorong pertumbuhan mikroorganisme dengan cepat (Zulkarnain 2009), sehingga akan mengganggu pertumbuhan dan perkembangan eksplan hingga menyebabkan kematian.

\section{Pertumbuhan tunas}

Teknik perbanyakan kultur jaringan yang diterapkan dalam penelitian ini dilaksanakan melalui kultur tunas. Inisiasi eksplan saninten berupa bagian apeks dengan satu ruas daun pertama dalam media pre-kondisi WPM dengan BAP $0.5 \mathrm{mg} / \mathrm{L}$ ternyata mampu memunculkan tunas aksilar. Tunas aksilar tersebut tumbuh sebagai respon pemanjangan tunas ketiak pada eksplan. Saninten merupakan jenis tanaman berkayu, sehingga dalam penelitian ini media yang digunakan ialah media WPM. Selain media dan jenis eksplan yang digunakan, penambahan ZPT juga berpengaruh pada keberhasilan kultur jaringan (Herawan et al. 2014).

Pemindahan eksplan steril hasil inisiasi ke media induksi dengan penambahan ZPT bertujuan untuk memperbanyak atau menggandakan tunas. Eksplan saninten dalam media WPM tanpa ZPT (kontrol) dan media WPM dengan IAA $0.2 \mathrm{mg} / \mathrm{L}$ tidak menghasilkan tunas. Pada media kontrol, tidak adanya kandungan ZPT eksogen membuat eksplan tidak mampu memproduksi tunas. Kondisi tersebut memperlihatkan bahwa secara fisiologis kandungan sitokinin endogen dalam eksplan sangat rendah. Pada media WPM dengan IAA $0.2 \mathrm{mg} / \mathrm{L}$, tidak adanya kemunculan tunas dapat disebabkan oleh dominasi ZPT auksin eksogen yang mengalahkan kerja sitokinin endogen pada eksplan. Hendaryono dan Wijayani (2012) menyatakan bahwa pembentukan tunas akan terjadi ketika konsentrasi sitokinin lebih tinggi dari auksin.

Menurut Hendaryono dan Wijayani (2012), keseimbangan antara auksin dan sitokinin sangat penting dalam menginduksi tunas karena masingmasing zat tersebut mempunyai peranan dalam menginduksi tunas. Media dengan kombinasi BAP $(0.5-1 \mathrm{mg} / \mathrm{L})$ dan IAA $(0.1-0.2 \mathrm{mg} / \mathrm{L})$ menghasilkan persentase bertunas dan jumlah tunas yang hampir sama. Kondisi tersebut dapat terjadi karena belum tercapainya keseimbangan konsentrasi BAP dan IAA yang ditambahkan ke dalam media untuk memunculkan tunas pada eksplan saninten.

Selain kemunculan tunas, pertambahan tinggi tunas pada eksplan yang dikulturkan dapat menunjukkan potensi morfogenesis dan kemampuan adaptasi tumbuhan terhadap lingkungannya, serta kapasitas pertumbuhan eksplan (Prihartini 2004). Auksin memiliki peranan dalam pemanjangan sel, sedangkan sitokinin berperan dalam pembelahan sel (Sulistiani dan Yani 2012). Dalam penelitian ini, kombinasi sitokinin (BAP 0.5-1 mg/L) dan auksin (IAA $0.1-0.2 \mathrm{mg} / \mathrm{L}$ ) yang digunakan menghasilkan pertumbuhan tinggi yang fluktuatif. Hanya pada media WPM dengan BAP 0.5 $\mathrm{mg} / \mathrm{L}$ yang mampu menghasilkan pertambahan tinggi tunas yang paling baik. Ketika konsentrasi BAP dinaikkan menjadi $1 \mathrm{mg} / \mathrm{L}$ justru terjadi penurunan tinggi tunas. Pada perbanyakan gaharu, kondisi serupa terjadi akibat periode inkubasi terlalu lama pada media yang mengandung sitokinin sehingga menyebabkan perpanjangan tunas terhambat (Azwin et al. 2006). Pada induksi biji manggis (Harahap et al. 2014) penggunaan 
BAP terlalu tinggi sebesar $10 \mathrm{mg} / \mathrm{L}$ menghasilkan pertumbuhan tunas yang kerdil. Selain itu, pada beberapa jenis tanaman dengan pertumbuhan lambat (slow growing), sifat pertumbuhan alami tanaman dapat mempengaruhi keberhasilan kutur in vitro (Yelnitis dan Joni 2015).

Media WPM dengan BAP $0.5 \mathrm{mg} / \mathrm{L}$ merupakan media dengan persentase bertunas, jumlah tunas dan pertambahan tinggi tunas paling baik. Konsentrasi BAP $0.5 \mathrm{mg} / \mathrm{L}$ merupakan konsentrasi ZPT yang digunakan pada media pre-kondisi awal. Kemungkinan eksplan tunas saninten sudah adaptif dengan kandungan ZPT BAP $0.5 \mathrm{mg} / \mathrm{L}$ sehingga mampu menghasilkan kondisi pertunasan dan pertambahan tinggi tunas paling baik. Menurut Gunawan (1992), terkadang eksplan dapat memiliki kemampuan tumbuh dan multiplikasi sel tanpa pemberian auksin ketika telah lama dipelihara dan disubkultur beberapa kali. Kemungkinan besar dalam sel-sel tersebut telah terjadi peningkatan level auksin, sehingga tidak memerlukan auksin dari luar. Sel-sel demikian disebut sel-sel yang habituated.

\section{Pertumbuhan kalus}

Respon yang diperlihatkan pada kultur saninten lainnya ialah kemunculan kalus pada eksplan. Beberapa kultur pada semua perlakuan dapat memunculkan kalus pada umur 8 MST, kecuali pada media tanpa ZPT (kontrol). Pembentukan kalus tidak terjadi dalam media kontrol, disebabkan oleh tidak adanya ZPT auksin eksogen pada media, sehingga sel tidak terpacu untuk membentuk kalus. Waktu awal munculnya kalus terjadi pada 10-14 HST hampir terjadi pada seluruh perlakuan. Pada waktu tersebut diduga eksplan telah merespon kerja auksin yang ditambahkan ke dalam media perlakuan.

Respon eksplan pada media kombinasi sitokinin (BAP 0.5-1 mg/L) dan auksin (IAA 0.1-0.2 mg/L) menghasilkan persentase eksplan berkalus yang fluktuatif, sedangkan penambahan konsentrasi IAA 0.1 menjadi $0.2 \mathrm{mg} / \mathrm{L}$ menunjukkan hasil pertambahan persentase eksplan berkalus. Sama halnya dengan produksi tunas dan tinggi tunas, kombinasi konsentrasi BAP dan IAA dalam penelitian ini belum mencapai keseimbangan yang optimal untuk merangsang pembentukkan kalus. Penggunaan auksin secara tunggal lebih memacu pertumbuhan kalus. Hal tersebut dikarenakan auksin memiliki peranan dalam menginduksi pembentukan kalus (Lesari 2011). Hingga akhir pengamatan, umumnya kalus yang terbentuk pada seluruh perlakuan (kecuali kontrol) belum mampu berdiferensiasi menjadi tunas. Diferensiasi kalus yang terjadi hanya membentuk organ berupa akar, yaitu pada satu eksplan dalam media WPM dengan IAA $0.1 \mathrm{mg} / \mathrm{L}$.

Selama fase induksi tunas, terdapat perubahan eksplan berupa kematian tunas dan kontaminasi. Kematian tunas awalnya disebabkan oleh munculnya metabolit sekunder dari eksplan berupa zat fenolik. Eksplan tersebut akhirnya mengalami kematian pada umur 8 MST. Zat fenolik ini juga yang menyebabkan perubahan warna kalus pada eksplan yang semakin menghitam ketika kultur semakin lama dalam media. Kontaminasi pada beberapa kultur yang steril dapat disebabkan oleh agen kontaminan yang telah bertahan di dalam jaringan sampai kondisi yang menguntungkan untuk pertumbuhannya (kontaminan laten) (Zulkarnain 2009) maupun akibat proses subkultur eksplan ke media induksi yang kurang teliti.

Keseimbangan konsentrasi ZPT sitokinin dan auksin yang digunakan belum memperlihatkan pertumbuhan tunas yang maksimal. Menurut Mesa et al. (2002), konsentrasi BAP rendah namun mampu menghasilkan pertumbuhan tunas dapat dipilih sebagai konsentrasi yang diterapkan dalam perbanyakan tunas agar tercapai efektivitas dan efisiensi biaya.

\section{SIMPULAN DAN SARAN}

\section{Simpulan}

Kombinasi ZPT BAP $(0,0.5,1 \mathrm{mg} / \mathrm{L})$ dengan IAA $(0,0.1,0.2 \mathrm{mg} / \mathrm{L})$ belum menghasilkan pertumbuhan tunas yang optimal. Media WPM dengan BAP $0.5 \mathrm{mg} / \mathrm{L}$ mampu menghasilkan persentase eksplan bertunas, jumlah tunas, dan pertambahan tinggi tunas terbaik. Media WPM dengan IAA konsentrasi 0.1 dan $0.2 \mathrm{mg} / \mathrm{L}$ menghasilkan pertumbuhan eksplan ke arah pembentukan kalus.

\section{Saran}

Perlu dilakukan pengkajian lebih lanjut dalam penggunaan BAP $0.5 \mathrm{mg} / \mathrm{L}$ dengan selang konsentrasi IAA yang lebih rendah agar didapatkan keseimbangan penggunaan ZPT dalam menghasilkan pertumbuhan tunas yang maksimal.

\section{DAFTAR PUSTAKA}

Ardiansyah R. 2015. Mikropropagasi tembesu (Fagraea fragrans ROXB) [tesis]. Bogor (ID): Institut Pertanian Bogor.

Azwin, Siregar IZ, Supriyanto. 2006. Penggunaan BAP dan TDZ untuk perbanyakan tanman gaharu (Aquilaria malaccensis Lamk.). Media Konservasi 11(3):98-104.

Fitria NF. 2015. Stek pucuk saninten (Castanopsis argentea BLUME) menggunakan ZPT komersial dan jenis media tanam yang berbeda [skripsi]. Bogor (ID): Institut Pertanian Bogor.

Gunawan LW. 1992. Teknik Kultur Jaringan Tumbuhan. Bogor(ID): PAU IPB Pr.

Harahap F, Poerwanto R, Suharsono, Suriani C, Rahayu S. 2014. In vitro and rooting of mangosteen (Garcinia mangostana L.) on medium with different concentrations of plant growth regulator. Hayati $J$ Bioscience 21(4):151-158.

Hendaryono DPS, Wijayani A. 2012. Teknik Kultur Jaringan: Pengenalan dan Petunjuk Perbanyakan Tanaman Secara VegetatifModern. Yogyakarta (ID): Kanisius. 
Herawan T, Putri AI, Ardhany F, Widowati TB. 2014. Pertumbuhan dan perkembangan kalus embriogenik Eucalyptus pellita menggunakan teknik embriogenesis somatik. Dalam Prosiding Seminar Nasional Benih Unggul untuk Hutan Tanaman, Restorasi Ekosistem, dan Antisipasi Perubahan Iklim, 2014 Nov 19-20, Yogyakarta, Indonesia. Bogor (ID): SEAMEO BIOTROP. hlm 287-294.

Heriyanto NM, Sawitri R, Subandinata D. 2007. Kajian ekologi permudaan Saninten (Castanopsis argentea (Bl) A.DC.) di Taman Nasional Gunung Gede Pangrango, Jawa Barat. Buletin Plasma Nutfah 13 (1):34-42.

Khairunisa R. 2009. Penggunaan beberapa jenis sitokinin terhadap multiplikasi tunas dan pertumbuhan binahong (Anredera cordifolia [Ten.] Steenis) [skripsi]. Bogor (ID): Institut Pertanian Bogor.

Lestari EG. 2008. Kultur Jaringan: Menjawab Persoalan Pemenuhan Kebutuhan akan Peningkatan Kualitas Bibit Unggul dan Perbanyakan secara besar-besaran. Bogor (ID): Penerbit Akademia.

Mansur I. 2013. Teknik Silvikultur untuk Reklamasi Lahan Bekas Tambang. Bogor (ID): SEAMEO BIOTROP.

Martawijaya A, Kartasujana I, Mandang Y, Prawira SA, Kadir K. 1989. Atlas Kayu Indonesia, Jilid II. Bogor (ID): Badan Penelitian dan Pengembangan Kehutanan. Departemen Kehutanan Bogor.
Mesa D, Romero A, Cruz AM. 2002. Study of differnet benzylaminopurine (BAP) concentrations in the in vitro micropropagation of Leucaena leucocephala cv Peru. Cuban J Agriscience 36(3):261-264.

Prihartini R. 2004. Pengaruh posisi penanaman eksplan terhadap pertumbuhan tunas aksilar bambu apus (Gigantochloa apus (J.A \& J.H Schultes) Kurz) [skripsi]. Depok (ID): Universitas Indonesia.

Sulistiani E, Yani SA. 2012. Produksi bibit tanaman dengan menggunakan teknik kultur jaringan. Bogor (ID): SEAMEO BIOTROP.

Wibowo C. 2006. Hubungan antara keberadaan saninten (Castanopsis argentea BLUME) dengan beberapa sifat tanah: kasus di Taman Nasional Gunung Gede Pangrango, Jawa Barat [disertasi]. Bogor (ID): Institut Pertanian Bogor.

Yelnitis, Joni M. Penggunaan BA, kinetin, dan thidiazuron dalam pembentukan tunas kulim (Scorodocarpus borneensis Becc). Dalam Prosiding Seminar Nasional Biosains 2: Penguatan Biologi sebagai Ilmu Dasar untuk Menunjang Kemajuan Sains dan Teknologi. 2015 Nov 19-20, Denpasar, Indonesia. Denpasar (ID): Universitas Udayana. hlm 52-59.

Zulkarnain. 2009. Kultur Jaringan: Solusi Perbanyakan Tanaman Budidaya. Jakarta (ID): Bumi Aksara. 